\title{
VEGETABLE (Starch) GLUE
}

Revised May 1950
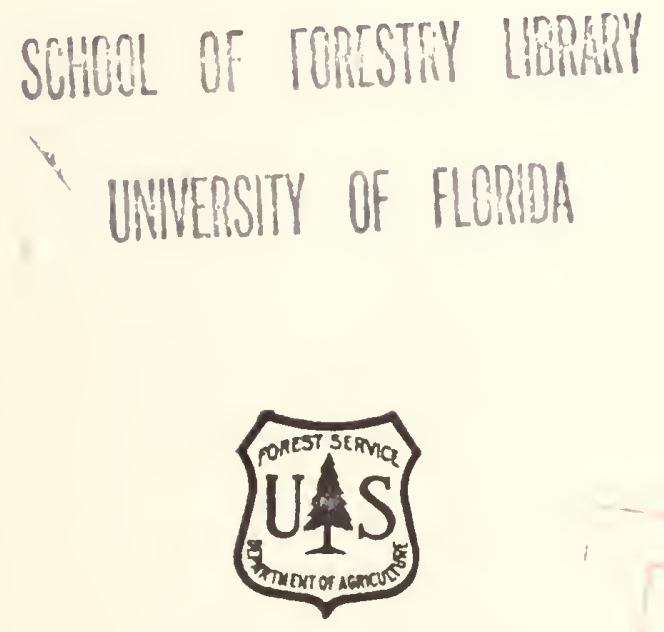

No. R30

UNITED STATES DEPARTMENT OF AGRICULTURE 2l. S, FOREST SER VICE FOREST PRODUCTS LABORATORY $M$ adis on 5 , Wis c on $s$ in In Cooperation with the University of Wisconsin 
Digitized by the Internet Archive in 2013

http://archive.org/details/starchg00fore 
By

Forest Products Laboratory, I Forest Service

U. S. Department of Agriculture

Summary

Vegetable glues are used in woodworking mainly for making plywood and other veneered products for interior use, but they have found some application in edge gluing and in certain assembly o erations. These glues are usually preared by the user by heating the vegetable-starch powder with water and then cooling the mixture to room temerature before use. Some prerared vegetable glues for wodworking rave been made available in liquid form, ready for use. Vegetable glues are room-temperature-setting and cievelop their strength by loss of water. They produce joints of high dry strength but with low water and moisture resistance.

\section{Introduction}

The information presented here on the comosition of vegetable glue has been obtained largely from the literature, from vatents, and from manufacturers and users of such glues, while the informution concerning the methods of usine vegetable glue for joijing wood is based in part on experiments at this Laboratory and in part on observations of its use in woodworking factories.

\section{Source of Vegetable Glue}

The raw material for vegetable glues is starch, a carbohydrate occurring abundantly throughout the vegetable world. The use of starch in the food industry is much greater than is its use in woodworking glues. It is sometimes found isolated in large quintities und in a high degree of purity in certain jiant organs, such as the stems of the sago palm, the fruit of the banank, the seeds of wheat and corn, and the roots of the potato, arrowroot, and cassava. Starch is the rrinciral form in which plants store food for future requirements.

I Maintained at Madison, Wis., in cooneration with the University of Wisconsin. 
In spite of its great variety and wide distribution in nature, there are comparatively few sources of commercial starch. amount manufactured in the United States is made from corn, which averages about 55 percent starch. Considerable potato starch is also made in this country, as well as some wheat starch. Tapioca (cassava) and sago starches are imported to some extent from the Far East. The latter is used narticularly in the manufacture of envelope gums. Cassava starch is noted for the uniformity of its paste. Of these starches, cassava is most often used in the production of vegetable glues for woodworking, although other starches can be used for this purpose.

The general principles? of starch manufacture are: (a) Disintegrating the plant tissue in such a way that the starch grains are set free but not ruptured; (b) separating the starch from the gluten by diluting with water the disintegrated mixture, which has been previously treated with chemicals or subjected to fermentation, and by then settling out the heavy starch by subsidence; (c) washing the starch by agitating with water in tanks, "running," or decantation; (d) recovery of the starch by draining in clothbottom boxes or in deep frame filter presses; and (e) drying the starch in kilns.

The starches from different sources will, of course, vary in certain properties; and, in addition, there may be variations in the starch from any one source depending upon growth conditions and on the methods and the care used in the production. Some of the starches, such as cassava, are marketed in different grades, and it is reported that the grade of the starch influences the properties of the adhesive.

\section{Development of Adhesives from Starch}

The use of adhesives from starches or sugars is supposedly a very ancient practice, although in woodworking industries it is a comparatively recent one. In connection with the early history of naper making it is said that the Egyptians used thin sheets of papyrus bound together with an adhesive made from a starch base. It is further reported that Chinese, centuries ago, used starch in some form for gluing wood. In more recent times attempts were made to use sugars as a base for an adhesive. In 1891 a patent was granted to Higgins on an adhesive of dextrin and borax, and another in 1894 to Wagner on an adhesive of dextrin, copper sulphate, sugar, and nitric acid. An early United States patent on the use of starch as an adhesive was issued to Murphy in 1896. Bloede revorts that a French natent was issued to Gerard in 1874 on a glue consisting of 1 part potato starch, 5 parts water, and 0.08 part caustic soda. It is probable that these earlier adhesives did not have sufficient strength to warrant their use as glues for woodworking. In 1908 a patent covering vegetable glue was issued to Frank G. Perkins. Under this and later patents the Perkins company

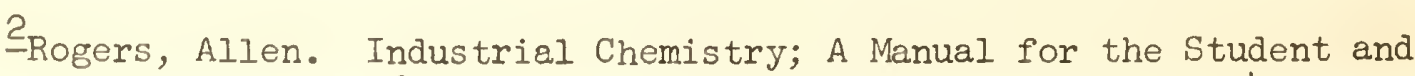
Manufacturer. 6 th ed. Van Nostrand, New York City. 1942. 
started the commercial production of vegetable glue for woodworking. More recently, still other natents on improvements in vegetuble glue have been issued to Tunnell, Bloede, and others.

\section{Sources of Cassava}

Cassava belongs to a class of woody shrubs and is related, botanically, to the rubber tree. It will attain a height of 12 to 16 feet. Two-year old plants are generally used, however, and at this time they are ordinarily 6 to 10 feet in height. The roots are tuberous, resembling a giant sweet notato, and it is from these roots that the starch is obtained. Cassava probably originated in Brazil, but it has reached its greatest production in Java; and it is from Java that the bulk of the present supply is received.

The raw starch may be converted directly into an adhesive, or it may receive an intermediate treatment known as "processing." The bulk of the vegetable glue used in woodworking has been made from so-called processed starch. The relative amounts of the processed and raw starches used at the present time are unknown.

\section{Frocessing}

Starch is often processed before its final conversion into glue for the purposes of: (I) Making it more soluble by modifying the outer wall of the starch grain, (2) reducing its water-absorbing quality and thus producing a glue of low water content, and (3) producing a uniform product.

The processing may consist of digesting the starch in hot water acidified with sulphuric acid and of later neutralizing the acid, or of treating the starch with sodium peroxide and later neutralizing the alkali. The processed starch is then drained and dried. These are only two of several methods of processing, most of which are covered by patents or carefully guarded as trade secrets.

\section{Preparation of the Adhesive}

Whether the basic material is a raw starch, a nrocessed starch, or a starch to which chemical ingredients have been added, the preparation of an adhesive ordinarily follows one of three general methods. These are treatmont with (1) caustic soda and heat, (2) caustic soda alone, or (3) heat alone.

If both caustic soda and heat are used, the amount of caustic is commonly in the neighborhood of 3 percent (vased on the weight of the dry starch), although it may be varicd to mect special requirements. A temerature in the general neighborhood of $150^{\circ} \mathrm{F}$. is required to convert such a mixture. 
When the conversion depends on the action of caustic soda alone, about 7 percent caustic is customary, although variations of 6 percent to 10 percent are not uncommon.

A temperature of about $150^{\circ} \mathrm{F}$. will convert the starch without the addition of caustic soda.

The amount of water used depends upon the variety and previous treatment of the starch. Processed starches or those containing added chemicals usually require a starch-water ratio of $1: 1.2$ to $1: 2.5$. If the raw starch is used, the proportion of water may be somewhat higher (such as 1:3.5). The use of a starch-water ratio of $1: 14$ to $1: 20$ is revorted for the preparation of a vegetable-glue size.

The caustic soda in the mixture produces the stringiness that is desirable in this class of glues. The glue without caustic or other chemicals resernbles paste, but good joint strengths can be obtained with it. The higher percentages of caustic cause the glue to set somewhat more slowly, and this allows the use of longer assembly times but requires a somewhat longer time in the clamps. Furthermore, the higher is the percentage of caustic, the greater is the danger of staining such woocis as oak, maple, cherry, elm, ash, birch, and beech. For these reasons a comrromise is usually made, under which the first method is most generally usea.

The equipment commonly used for the preparation of vegetable glue consists of a mechanical mixer surrounded by a steam-heated water jacket. It is possible, but not at all convenient, to prepare small batches of these glues over a water bath with hand stirring. The general procedure for conversion of starch into an adhesive is as follows:

The required amount of water is poured into the mixer, the starch is added, and the mass is stirred until any lumis have been broken. The stirring is continued while the caustic soda (previously dissolved in about three times its weight of water) is slowly added. Steam is now turned into the water jacket, and the temperature is increased gradually (the stirring being continuous) until the water in the jacket is somewhere between $190^{\circ}$ and $200^{\circ} \mathrm{F}$. (This is, of course, considerably in excess of the temperature required to convert the starch, but a considerable temerature gradient will exist between the water jacket and the center of the irner container, so that the average temperature of the starch susvension is not greatiy in excess of $\left.150^{\circ} \mathrm{F}.\right)$ About one-half hour is required to bring the temperature of the water jacket from room temperature to $200^{\circ} \mathrm{F}$. At the end of this time it will be noticed that the starch has changed in appearance from a white suspension to an amber-colored stringy paste. If picked up on a paddle and held to the Jight, it will appear almost transparent. When it reaches this stage, the conversion is stopped by turning off the steam and by replacing the hot water in the water jacket wi.th cold. The stirring of the glue is continued until the temperature has been reduced to about that of the room. The glue is now ready for use. Details of the general proccdure given above may be varied under the instructions of the glue manufacturer according to the chemical additions and to the grade or previous treatment of his starch. 
When a starch suspension is overheated, therc scems to be some danger of an undesirable chemical change in the nature of the paste. This change has been called caramelization, and it is characterized by a reddish-brown coloration in the glue. No attemot will be made to explain the exact nature of this change; the result is said to be a reduction in the adhesive nower of the glue. In the proparation of a starch adhcsive, this caramelization is guarded against by: (1) Adding the caustic soda to the starch suspension before applying heat, (2) controlling the temperature of the water bath during the mixing operation, and (3) stopping the conversion when the adhesive has reached the transparent, amber-colored, stringy stage.

\section{Application of Vegetable Glue}

Vegetable glue is very viscous and difficult to spread by hand, but on a mechanical spreader it works very well. The mixtures commonly used dry slowly, and their working life is very long. In lant operations, the glue remaining from a day's run may be left in the spreader, the spreador be covered with a damp cloth at night, and fresh gluc be added in the morning. Joints have been made in the laboratory with glue that has stood for 42 days after mixing, and the resulting strength has been $\in$ ntirely satisfactory. This slow rate of change in viscosity enables the manufacturer to use a long assembly time in gluing, which is particularly desirable in the production of plywood. However, this same characteristic of slow setting is sometimes a disadvantage in joint work where the stock is often under pressure for only a short time.

Tests based on the more common types of vegetable glues have shown that the strength of joints increases slowly during the first 2 hours after pressure is applied. During the period of 2 to 6 hours after applying the pressure, the rate of increase is somewhat nore ranid, and after about 8 hours it becomes more gradual again. Joints of animal glues, casein glues, and some of the never vegetable glues will increase in strength more rapidly. In thick stock, the joint will be strong enough for machining after about 7 hours, but 2 hours in the press is sufficient, provided that the joint is allowed to condition further for a day before machining. In veneer work, the best rcsults may be expected if the joints are left under pressure overnight and are then removed and allowed to dry or to condition thoroughly.

Although most of the vegetable glues are slow in setting and all that have come to our attention are low in moisture resistance, attempts are being made constantly by the producers to improve their glues in these respects. Manufacturers have prepared starch glues that show a more rapid increase in joint strength than do the ordinary starch-caustic mixtures. The attemts to produce a water-resistant starch glue have not, so far as is known, met with success.

Experiments conducted at the Forest Products Laboratory with a good grade of glue have sinown that a spread of about 45 square feet of single glue line per pound of dry glue can be depended uron to produce very satisfactory 
results with normal conditions of pressure and assembly time. The spread may, of course, be varied, but a decrease in the strength of the joint will probably be noticed if the amount of glue is cut so as to get more than 55 or 60 square feet of glue line per pound of dry glue. On the other hand, there is some danger in increasing the amount of glue spread too much because of the amount of water added during the gluing operation. Vegetable glue, after being spread on the wood, ordinarily remains in a condition satisfactory for pressing for periods up to about 25 minutes. A pressure of about 200 pounds per square inch gives good results when the assembly time varies over a rather wide range. In commercial operations, however, a pressure of from 100 to 150 pounds per square inch is commonly used with success. If the assembly time is short, say from 1 to 5 minutes, a pressure of about 100 pounds per square inch may give slightly stronger joints than one of 200 pounds per square inch. Since vegetable glues generally contain large proportions of water, it is usually necessary to recondition glued stock after removal from pressure before further machining or finishing. Glued stock for interior use should have a moisture content of 6 to 8 percent before final machining.

\section{Durability of Vegetable-glue Joints}

Vegetable glues are generally low in water resistance and are very similar to animal glues in this resnect. Conventional shear-test specimens of yellow birch plywood (three-ply, 3/16-inch) bonded with a tyoical vegetable glue were exposed under each of several repeating cycles. The cycles consisted of exposure, at a temperature of $80^{\circ} \mathrm{F}$. for each thase, for 14 days at a high relative humidity or of soaking in water for 2 days, followed by exposure for 12 or 14 days at 30 nercent relative humidity. Such cycles caused swelling and shrinking of the wood and subsequent mechanical stresses on the joints. At some of the higher relative-humidity conditions softening of the glue also occurred. The exposure cycles are given in table 1 .

Specimens subjected to test No. 6 (table 1) separated completely, either in the first cycle or in the drying that immediately followed. Specimens exposed to test No. 5 showed at the end of the first complete cycle an average joint strength of less than 40 percent of the original. All specimens failed before the end of the fourth cycle, or in somewhat less than 16 weeks. A relative humidity of 97 percent is sufficiently high to permit development of molds and to bring the moisture content of the wood to about 28 percent during the wet half of the cycle.

Specimens exposed to test No. 4 failed less rapidly than those exposed to test No. 5. They had decreased in strength, however, by some 50 percent by the end of the first test cycle, and all specimens had failed by the end of 36 weeks. Moisture content of the wood during the wet half of this cycle probably reached about 22 percent.

In test No. 3, more than 20 weeks of exposure were required before the average test values had fallen to 50 percent of the original. By the 
end of the 81 weeks, however, all specimens had failed, which indicated that vegetable-glue joints cannot be depended upon to remain permanently durable when exposed to conditions under which the wood may at times exceed about 17 percent moisture content, which is approximately the equilibrium condition for 80 percent relative humidity. Furniture and other products bonded with vegetablc glues often serve satisfactorily in spite of occasional exposures to relative humiditics in excess of 80 percent, but in those cases protection afforded uy the finish may prevent the moisture content of the wood from reaching equilibrium values, particularly if the exposure to dampness is not prolonged.

In tests Nos. 1 and 2, no evidence of significant loss in strength could be detected during the 160 weeks that the tests were in progress. Test INo. 2 Epproximates the changes in moisture content that can be expected in interior woodwork in normal use in heated buildings in the northern part of the United States. In this type of scrvice, properly designed and well-made joints of vegetable glue should prove :ermanently durable, and experimental evidence, other than these tests, supports that belief.

\section{Uses of' Vegetable Glue}

Vegetable glue is utilized chiefly in plywood and other veneered products manufactured for interior use, such as furniture of all kinds, pianos, and interior trim. Because of their slow setting the ordinary vegetable glues are not extensively used in edge-joint gluing, but it is reported that the increased settjing rate of some of the newer types has allowed vegetable glues to compete successfully in this field.

The lack of water resistance prevents the use of vegetable glue in products that will be subjected to moist conditions.

\section{Starch Tests}

Although research on starch has been extensive, no simple chemical or mechanical test has been devised that will permit the user to test starch for quality and for suitability for gluemaking.

If it is desired, the starches may be distinguished from each other by such tests as the temperature of gelatinization, by the form and size of the grain, by the appearance under polarized light, by the refractive inaex, by the character of the paste, by the color reactions, and probably by X-ray determinations of the crjstal structure.

Consistency tests at different starch-water ratios may give useful information, but the user of the glue must, for the most fart, rely upon joint tests in determining the quality of starch for gluemaking. 
Table 1.--Exposure cycles of yellow birch plywood bonded with vezetable giue

\begin{tabular}{|c|c|c|c|c|c|c|c|c|c|}
\hline \multirow{4}{*}{ Test } & : & \multirow{4}{*}{$\begin{array}{c}\text { Type of } \\
\text { exposure cycie }\end{array}$} & \multicolumn{3}{|c|}{ : First stage } & \multicolumn{4}{|c|}{ : Second stage } \\
\hline & : & & \multicolumn{7}{|c|}{ 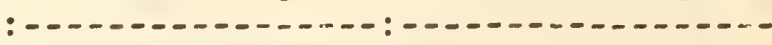 } \\
\hline & : & & : Time & : & Relative & : & Time & : & Relative \\
\hline & : & & & : & humidity & : & & : & humidity \\
\hline \multicolumn{10}{|c|}{ Devs: Percent } \\
\hline & : & & : Days & : & Percent & : & Days & : & Percent \\
\hline \multirow{3}{*}{1} & & & $:$ & : & & : & & : & \\
\hline & : & Continuous (controls) & $\therefore \ldots$. & : & 30 & : & $\cdots \cdot$ & : & $\ldots \ldots \ldots$ \\
\hline & : & & : & : & & : & & : & \\
\hline \multirow[t]{2}{*}{2} & : & Alternating & 14 & : & 60 & : & 14 & : & 30 \\
\hline & : & & : & : & & : & & : & \\
\hline \multirow[t]{2}{*}{3} & : & ........do......... & 14 & : & 80 & : & 14 & : & 30 \\
\hline & : & $\cdot$ & : & : & & : & & : & \\
\hline \multirow[t]{2}{*}{4} & : & ........do......... & 14 & : & 90 & : & 14 & : & 30 \\
\hline & : & & : & : & & : & & : & \\
\hline \multirow[t]{2}{*}{5} & : & ........ ào......... & 14 & : & 97 & : & 14 & : & 30 \\
\hline & : & & : & : & & : & & : & \\
\hline \multirow[t]{2}{*}{6} & : & ................. & 2 & : & (1) & : & 12 & : & 30 \\
\hline & $:$ & & $:$ & : & & $:$ & & : & \\
\hline
\end{tabular}

ISoaked in water at room temperature. 